\title{
Diurnal and bathymetric changes in chlorophyll fluorescence yields of reef corals measured in situ with a fast repetition rate fluorometer
}

\author{
Michael P. Lesser ${ }^{1, *}$, Maxim Y. Gorbunov ${ }^{2}$ \\ ${ }^{1}$ University of New Hampshire, Department of Zoology and Center for Marine Biology, Durham, \\ New Hampshire 03824, USA
}

${ }^{2}$ Environmental Biophysics and Molecular Ecology Program, Institute of Marine and Coastal Sciences, Rutgers University, 71 Dudley Road, New Brunswick, New Jersey 08901, USA

\begin{abstract}
A newly developed underwater fast repetition rate fluorometer (FRRF) was used for in situ measurements of chlorophyll fluorescence yields on the reef-building corals Montastraea faveolata and Montastraea cavernosa from around Lee Stocking Island, Bahamas. Diel studies of the quantum yield of chlorophyll fluorescence $\left(\Delta F^{\prime} / F_{\mathrm{m}}\right)$ in photosystem II (PSII) reveal a pattern of mid-day depression of $\Delta F^{\prime} / F_{\mathrm{m}}$ ' in both of these species of coral. At the same time, non-photochemical quenching $(q N)$ increased significantly during the day, a pattern consistent with the regulation of PSII by dynamic photoinhibition mediated by non-photochemical quenching. Despite these mid-day depressions in $\Delta F^{\prime} / F_{\mathrm{m}}{ }^{\prime}$, net productivity, measured as oxygen flux, remains high, suggesting that non-photochemical quenching dissipates the majority of the absorbed photons at mid-day and protects the photosynthetic apparatus, allowing the endosymbiotic dinoflagellates (zooxanthellae) to operate at maximum rates of photosynthesis. In 1999 measurements of $\Delta F^{\prime} / F_{\mathrm{m}}{ }^{\prime}$ on $M$. faveolata over a bathymetric range of 2 to $30 \mathrm{~m}$ showed an increase in $\Delta F^{\prime} / F_{\mathrm{m}}{ }^{\prime}$ with increasing depth when measured at the same time of day. This suggests, although there is year-to-year variability, that changes in the underwater light field, and photoacclimation to that light field, control the degree of photoprotection attributable to non-photochemical quenching in the zooxanthellae of these corals. The fluorescence yields of $M$. faveolata exposed to elevated temperatures $\left(>32^{\circ} \mathrm{C}\right)$ in the field showed a significant decrease in $\Delta F^{\prime} / F_{\mathrm{m}}$ ' before visible signs (e.g., paling of colonies) occurred. It was also possible to predict which colonies at the same depth and light regime would bleach first in response to elevated temperatures before any visible signs of bleaching were evident using $\Delta F^{\prime} / F_{\mathrm{m}}{ }^{\prime}$ as a predictor.
\end{abstract}

KEY WORDS: Chlorophyll fluorescence · Quantum yield $\cdot$ Coral · Coral bleaching

Resale or republication not permitted without written consent of the publisher

\section{INTRODUCTION}

The measurement of chlorophyll a fluorescence using active, versus passive (= solar induced), techniques is becoming the preferred, non-destructive, in situ method to assess how well photosystem II (PSII) is functioning in benthic marine photoautotrophs under a variety of environmental conditions. Chlorophyll a

*E-mail: mpl@christa.unh.edu fluorescence has been an important tool of photobiologists, starting with the discovery of fluorescence induction (Kautsky \& Hirsh 1931). Fluorescence measurements with and without using the herbicide 3(3,4-dichlorophenyl)-1,1dimethylurea (DCMU), which inhibits the reoxidation of $Q_{\mathrm{A}}^{-}$, the primary quinone electron acceptor of PSII (DCMU ratios), then became an important tool of photobiologists (Vincent 1980). Recently, instruments have been developed that measure chlorophyll fluorescence yields of PSII using multiple photochemical turnover (pulse amplitude modu- 
lated [PAM]), and single photochemical turnover protocols (pump-and-probe or fast repetition rate [FRR]) in the laboratory and in the field (Schreiber et al. 1986, Kolber et al. 1998, Gorbunov et al. 2000). These instruments also allow detailed quenching analyses to be performed on photoautotrophs under a variety of environmental conditions to understand the dynamics between photochemical and non-photochemical quenching. There are several theoretical discussions available on the relationship between chlorophyll fluorescence yields and photosynthetic parameters related to PSII (Genty et al. 1989, 1990, Krause \& Weis 1991, Kolber et al. 1998). One recent use of laboratory and in situ measurements of chlorophyll a fluorescence is in our understanding of the 'bleaching' phenomenon of reefbuilding corals and other benthic photoautotrophs harboring symbiotic microalgae or cyanobacteria. Damage to PSII, following exposure to elevated temperatures and solar radiation, is believed to be an important initiator of bleaching (Iglesias-Prieto et al. 1992, Lesser 1996, Warner et al. 1996, 1999). Bleaching results in the expulsion of photoautotrophic symbionts from their hosts in response to environmental perturbation, with elevated temperatures explaining most of the described bleaching events (Glynn 1993). Early laboratory work using DCMU ratios (Iglesias-Prieto et al. 1992, Lesser 1996) provided data that suggested acceptor side inhibition of PSII during acute and chronic exposures to elevated temperature in cultured symbiotic zooxanthellae. Lesser (1996) described damage to both PSII and the primary carboxylating enzyme, RUBISCO, which resulted in a decrease in productivity. Damage to these targets was correlated with the level of oxidative stress in zooxanthellae exposed to elevated temperatures, and productivity was partially restored when cultures were subsequently exposed to antioxidants. The photodynamic formation of singlet oxygen, superoxide radicals, and hydrogen peroxide are enhanced in chloroplasts during exposure to elevated temperatures and solar radiation. It is also well known that components of PSII and stromal enzymes (e.g., RUBISCO) are damaged by the accumulation of these reduced oxygen intermediates (Asada \& Takahashi 1987). Recent data provided by fluorescent measurements (PAM) and quenching analyses support the results described above, that there is damage to both the light and dark reactions (Jones et al. 1998). The cascade of events that ultimately induces the expulsion of zooxanthellae from their host could be initiated by the accumulation of reduced oxygen intermediates or a decrease in the amount of translocated photosynthate, as suggested by Lesser et al. (1990).

Warner et al. (1996) used a PAM instrument in the laboratory and observed damage to PSII during expo- sure to elevated temperatures on zooxanthellae in hospite, supporting the culture work described above. The species-specific differences of corals in their sensitivity to elevated seawater temperatures that Warner et al. (1996) described may also provide an explanation for the heterogeneous patterns of bleaching observed in the field. Additionally, recent work by Warner et al. (1999) has clearly shown that damage at the D1 protein of PSII occurs in zooxanthellae exposed to elevated seawater temperatures.

An underwater version of the PAM instrument is available and has been widely used to describe diel changes in the quantum yield of chlorophyll fluorescence in PSII and its relationship to photochemical and non-photochemical quenching (Brown et al. 1999, Hoegh-Guldberg \& Jones 1999, Ralph et al. 1999). Brown et al. (1999) suggested that the diurnal patterns in quantum yields and xanthophyll cycling they observed were indicative of photoinhibition followed by photoprotection. Hoegh-Guldberg \& Jones (1999) and Jones et al. (1998) observed similar patterns and suggested that sink limitations were also important in regulating the quantum yields of chlorophyll fluorescence in PSII.

The following work utilizes an underwater version of an FRR fluorometer (FRRF) recently described by Gorbunov et al. (2000). The instrument was configured to measure chlorophyll a fluorescence yields using single turnover protocols (Kolber et al. 1998). Using this instrument we describe changes in chlorophyll fluorescence yields with depth, diel changes in fluorescence yields and photosynthetic activity, and the use of fluorescence yields in situ to detect incipient bleaching in hermatypic corals before visible signs (i.e., colony paling) actually occur.

\section{MATERIALS AND METHODS}

Study site and sample collections. Experiments were performed at the Caribbean Marine Sciences Center, Lee Stocking Island (LSI), Bahamas $\left(23^{\circ} 46^{\prime} \mathrm{N}\right.$, $\left.76^{\circ} 05^{\prime} \mathrm{W}\right)$. In situ measurements of chlorophyll fluorescence yields and photosynthetic activity were performed at sampling sites around LSI in May 1998 and May 1999. Measurements of diel variability in chlorophyll fluorescence yields were conducted on samples $(\mathrm{N}=6)$ of the reef-building corals Montastraea faveolata and Montastraea cavernosa, from North Perry Reef (17 m depth, maximum irradiance in situ at noontime photosynthetically active radiation [PAR: 400 to $700 \mathrm{~nm}$ ] ca $500 \mu \mathrm{mol}$ quanta $\mathrm{m}^{-2} \mathrm{~s}^{-1}$ ) in May 1998 at 08:00, 12:00, 16:00, 20:00, and 23:00 h.

In situ measurements of chlorophyll fluorescence yields on the coral Montastraea faveolata were made 
over the bathymetric range of 3 to $23 \mathrm{~m}$. Measurements in 1998 were taken on corals $(\mathrm{N}=10)$ from Rainbow Garden (3 to $4 \mathrm{~m})$, Horseshoe Reef (10 m), North Perry Reef (12 and $17 \mathrm{~m})$, and Bock Wall $(23 \mathrm{~m})$ between 09:00 and 10:00 h on clear cloudless days. Measurements in 1999 were taken on corals $(\mathrm{N}=10)$ from Rainbow Garden (3 to $4 \mathrm{~m})$, Horseshoe Reef (10 m), North Perry Reef (17 m), and Bock Wall (23 and $30 \mathrm{~m})$ under similar conditions. Water temperatures normally varied between 26 and $29^{\circ} \mathrm{C}$ as measured by recording temperature thermistors (HOBO Temps, Onset Corporation). Additional temperature data were obtained from the Caribbean Marine Science Center temperature monitoring program at sites around LSI.

In the field, corals that had been measured during the bathymetric study at Rainbow Garden ( 3 to $4 \mathrm{~m}$ ) were tagged and re-measured during a time period when the temperature of the water surrounding LSI began to rise due to the intrusion of warm Bahama Bank water onto the Exuma Islands. Fluorescence measurements were taken on corals when seawater temperatures were elevated before and after visible bleaching occurred.

FRR fluorescence measurements. Chlorophyll fluorescence yields were measured using a custom-built FRRF (Gorbunov et al. 2000). FRR fluorometry measures chlorophyll fluorescence transients using a controlled series of sub-saturating flashes that cumulatively saturate PSII within $\sim 100 \mu \mathrm{s}$, i.e. a single photochemical turnover (Falkowski \& Kolber 1995, Kolber et al. 1998). The FRR technique can therefore measure several fluorescent parameters $\left(F_{0}, F_{\mathrm{m}}, F_{\mathrm{v}}, F^{\prime}\right.$ and $\left.F_{\mathrm{m}}{ }^{\prime}\right)$ and parameters related to photosynthesis $\left(F_{\mathrm{v}} / F_{\mathrm{m}}, \Delta F^{\prime} / F_{\mathrm{m}}{ }^{\prime}\right.$ and $\left.\sigma_{\mathrm{PSII}}\right)$ (see Table 1 and Gorbunov et al. 2000). All fluorescence measurements reported below were taken from the upper portion of each colony on the surface which provided the greatest pla-

Table 1. Symbols and abbreviations used throughout the text

\begin{tabular}{|ll|}
\hline$\sigma_{\mathrm{PSII}}$ & $\begin{array}{l}\text { Functional absorption cross-section for PSII } \\
F_{0}, F_{\mathrm{m}}\end{array}$ \\
$F_{\mathrm{v}}$ & $\begin{array}{l}\text { Minimum and maximum yields of chlorophyll a } \\
\text { fluorescence measured after dark acclimation } \\
\text { (relative units) } \\
\text { Variable fluorescence after dark acclimation } \\
\left(=F_{\mathrm{m}}-F_{0} \text { ) (dimensionless) }\right.\end{array}$ \\
$F_{\mathrm{v}} / F_{\mathrm{m}}$ & $\begin{array}{l}\text { Maximum quantum yield of photochemistry in } \\
\text { PSII measured after dark acclimation (dimen- } \\
\text { sionless) }\end{array}$ \\
$F^{\prime}, F_{\mathrm{m}}^{\prime}$ & $\begin{array}{l}\text { Steady-state and maximum yields of chlorophyll a } \\
\text { fluorescence measured under ambient light } \\
\text { (relative units) }\end{array}$ \\
$\Delta F^{\prime} / F_{\mathrm{m}}^{\prime}$ & $\begin{array}{l}\text { Quantum yield of photochemistry in PSII } \\
\text { measured at steady state under ambient light }\end{array}$ \\
\hline
\end{tabular}

nar surface to the incident downwelling light. This was done because it was found in preliminary work that within coral variability from the top down mirrored that seen in the bathymetric studies, suggesting within-colony microenvironments of exposure to solar radiation (M.P.L. unpubl.).

The maximum (i.e., potential) quantum yield of chlorophyll fluorescence, or photochemistry, of PSII is determined in a dark-adapted state as the ratio $F_{\mathrm{v}} / F_{\mathrm{m}}$ $\left(=\left[F_{\mathrm{m}}-F_{0}\right] / F_{\mathrm{m}}\right)($ Butler 1972) and taken from nighttime measurements during this study. Measuring the steady-state fluorescence level $\left(F^{\prime}\right)$ during a lightacclimated state allows other parameters related to the absorbance and dissipation of energy to be calculated. These include the steady-state quantum yield of chlorophyll fluorescence, or photochemistry, in PSII, $\Delta F^{\prime} / F_{\mathrm{m}}{ }^{\prime}\left(=\left[F_{\mathrm{m}}{ }^{\prime}-F^{\prime}\right] / F_{\mathrm{m}}{ }^{\prime}\right)$, and the coefficient of nonphotochemical quenching, $q N=1-\left(F_{\mathrm{m}}{ }^{\prime}-F^{\prime}\right) /\left(F_{\mathrm{m}}-F_{0}\right)$ (Genty et al. 1989, van Kooten \& Snel 1990). In addition to these parameters, which can also be measured using active fluorescence methods such as PAM, pump-andprobe, or FRR, the FRRF instantaneously measures the functional absorption cross-section of PSII $\left(\sigma_{\mathrm{PSII}}\right)$, which characterizes the capacity to absorb and utilize light (Kolber et al. 1998).

Characterization of the underwater light field. Visible and UV radiation (300 to $700 \mathrm{~nm}$ ) were measured over several days during May 1998 and May 1999 at $18 \mathrm{~m}$; in addition, simultaneous measurements of surface irradiance were made using a Li-Cor LI-1800UW scanning spectroradiometer (Li-Cor, Lincoln, NE) calibrated with National Institute of Standards and Technology (NIST) traceable standards. Hourly readings of 3 scans were taken and the mean reported in units of $\mathrm{W} \mathrm{m} \mathrm{m}^{-2} \mathrm{~nm}^{-1}$. The cosine-corrected collector and sensors were programmed to scan from 300 to $700 \mathrm{~nm}$ in $2 \mathrm{~nm}$ intervals. Vertical attenuation coefficients $\left(K_{\mathrm{d}}\right.$ $\mathrm{m}^{-1}$ ) for both visible and UV radiation were calculated as described by Kirk (1994).

Productivity measurements. Colonies $(\mathrm{N}=6)$ of Montastraea faveolata and $M$. cavernosa were collected from North Perry Reef (17 m depth), cleaned of all epibionts, and allowed to 'heal' for $48 \mathrm{~h}$ at their depth of occurrence. These samples were then placed in a self-contained, multichambered $(\mathrm{N}=6)$, underwater respirometer at the depth of collection for $24-36 \mathrm{~h}$ to obtain continuous oxygen flux and underwater irradiance data. The chambers were approximately $15 \mathrm{~cm}$ in diameter and $20 \mathrm{~cm}$ tall with a volume of $3.7 \mathrm{l}$. The chambers and lids were made of Plexiglas that transmits UVR $(100 \%$ cutoff at $275 \mathrm{~nm}, 50 \%$ cutoff at $305 \mathrm{~nm})$. All chambers were constantly stirred using hydraulically driven magnetic stirrers, and flushed at 60 min intervals to prevent supersaturation of the seawater with oxygen during the day. Changes in oxygen 


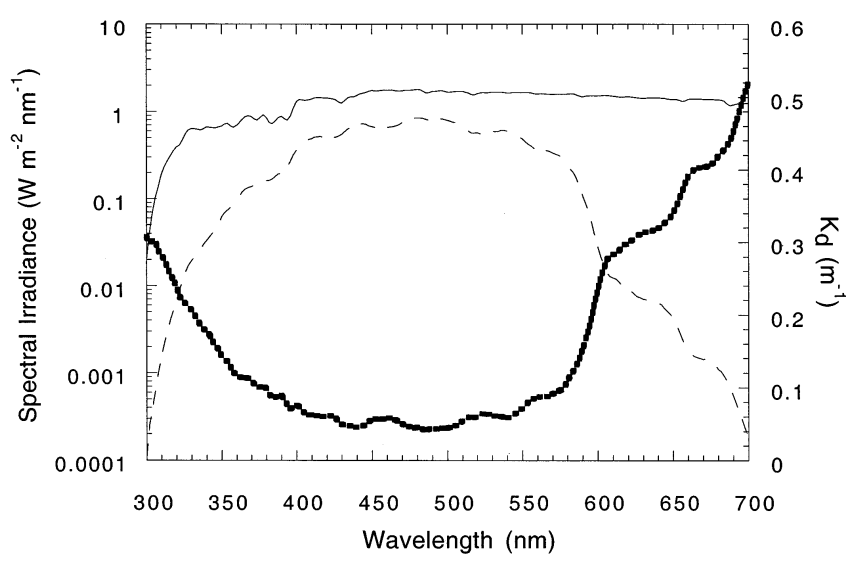

Fig. 1. Surface (-) and $17 \mathrm{~m} \mathrm{(-} \mathrm{-} \mathrm{-)} \mathrm{spectral} \mathrm{data} \mathrm{(300} \mathrm{to}$ $700 \mathrm{~nm}$ ) recorded on North Perry Reef, Lee Stocking Island, Bahamas, May 1998 ( 13:00 h). Calculated spectral attenuation coefficients $\left(K_{\mathrm{d}}\left[\mathrm{m}^{-1}\right]\right)$ found using the surface and $17 \mathrm{~m}$ data (thick solid line) are also shown

concentration were measured using calibrated temperature and pressure compensated polarographic electrodes (Yellow Springs Instruments, Inc.). The oxygen electrode polarization and the pump and solenoid controls were provided on a custom-designed printed circuit (Pamunkey Engineering Associates) in an Ikelite U/W housing. Data were collected and stored using a Li-Cor 1000 datalogger, also located in the Ikelite U/W housing, then downloaded to a computer as a text file and converted to oxygen concentrations and fluxes. The oxygen flux within each chamber was corrected for the volume displacement of each individual coral. PAR was recorded simultaneously with the oxygen flux measurements using an underwater cosine-corrected sensor (Li-Cor LI-192SA) at the depth of incubation. Net photosynthesis and respiration were normalized to colony surface area and calculated for the $30 \mathrm{~min}$ period on either side of the corresponding FRR measurements. Surface area was determined immediately after removal from the respirometer using the aluminum foil technique (Marsh 1970). Additionally, subsamples of each coral $(\mathrm{N}=6)$ that were approximately 3.0 to $5.0 \mathrm{~cm}^{2}$ were placed overnight in $100 \%$ acetone at $4{ }^{\circ} \mathrm{C}$ and the concentrations of chlorophyll a calculated as described above.

Statistical analysis. Measurements of the quantum yield of chlorophyll fluorescence, non-photochemical coefficients, and oxygen flux measurements were statistically analyzed using a 1-way ANOVA (fixed effect of time or depth) at a significance level of $5 \%$. No unequal variances were detected using the $F_{\text {max }}$ test, and individual treatment differences were assessed using the Student-Newman-Keuls (SNK) multiple comparison test. Where appropriate, ratios and per- centages were arcsin transformed for analysis and back transformed for presentation. The field measurements of fluorescence were analyzed using a Student's $t$-test.

\section{RESULTS}

Measurements of visible and UV radiation on North Perry Reef in 1998 showed little variability during the experimental period. Fig. 1 shows a typical measurement of surface and $17 \mathrm{~m}$ spectral scans from 300 to $700 \mathrm{~nm}$ on a cloudless day at midday $(\sim 13: 00 \mathrm{~h})$. The maximum surface PAR irradiance (integrated from 400 to $700 \mathrm{~nm}$ ) on that day was $2125 \mu \mathrm{mol}$ quanta $\mathrm{m}^{-2} \mathrm{~s}^{-1}$, while the maximum PAR irradiance at $17 \mathrm{~m}$ was $451 \mu \mathrm{mol}$ quanta $\mathrm{m}^{-2} \mathrm{~s}^{-1}$. Both the irradiance data and spectral attenuation coefficients at mid-day varied by less than $10 \%$ during the experimental period, suggesting that the optical properties of the water column changed very little during this time period. The average spectral attenuation coefficient for PAR wavelengths $\left(K_{\mathrm{d}}=0.17 \mathrm{~m}^{-1}\right)$ is on the higher end of those observed for Case I waters (Kirk 1994).

In situ measurements of chlorophyll fluorescence yields on Montastraea faveolata exhibited diel variations apparently driven by changes in ambient light (Fig. 2A). The in situ measurements revealed that dayto-day variation in night-time fluorescence yields are low, and the diurnal patterns of $F^{\prime}, F_{\mathrm{m}}{ }^{\prime}, \Delta F^{\prime} / F_{\mathrm{m}}{ }^{\prime}$, and $\sigma_{\mathrm{PSII}}$ were characterized by a decrease from high morning values to noon or late afternoon minimums, followed by a reciprocal increase after the daily minimum. For $M$. faveolata significant effects of time were observed (ANOVA: $\mathrm{p}=0.0001$ ) for $F^{\prime}, F_{\mathrm{m}}{ }^{\prime}, \Delta F^{\prime} / F_{\mathrm{m}}{ }^{\prime}$, and $\sigma_{\mathrm{PSII}}$. Post-hoc analyses for $F^{\prime}, F_{\mathrm{m}}{ }^{\prime}$, and $\Delta F^{\prime} / F_{\mathrm{m}}{ }^{\prime}$ showed that mid-day $(12: 00 \mathrm{~h})$ and afternoon $(16: 00 \mathrm{~h})$ values were significantly (SNK: $\mathrm{p}<0.05$ ) lower than all other measurements and not significantly different from one another (SNK: $p>0.05$ ). The functional absorption cross-section of PSII $\left(\sigma_{\mathrm{PSII}}\right)$ showed a similar pattern but with morning $(08: 00 \mathrm{~h})$ measurements significantly higher than late night (23:00 h) values. While the same general pattern of $F^{\prime}, F_{\mathrm{m}}{ }^{\prime}, \Delta F^{\prime} / F_{\mathrm{m}}{ }^{\prime}$, and $\sigma_{\mathrm{PSII}}$ was observed for $M$. cavernosa (Fig. 2B), the magnitude of the diel cycling was not as striking as observed in $M$. faveolata. Treatment effects on the quantum yield of chlorophyll fluorescence (= PSII photochemistry, $\Delta F^{\prime} / F_{\mathrm{m}}{ }^{\prime}$ ) were significant (ANOVA: $\mathrm{p}=0.003$ ), with only late afternoon $(16: 00 \mathrm{~h})$ values significantly lower than all others (SNK: $\mathrm{p}<0.05) . F^{\prime}$ exhibited no significant effect of time (ANOVA: $\mathrm{p}=0.17$ ), while $F_{\mathrm{m}}{ }^{\prime}$ was significant (ANOVA: $\mathrm{p}=0.037$ ) with early morning $(08: 00 \mathrm{~h})$ and early evening $(20: 00 \mathrm{~h})$ values significantly greater than all other measurements (SNK: $\mathrm{p}>$ 

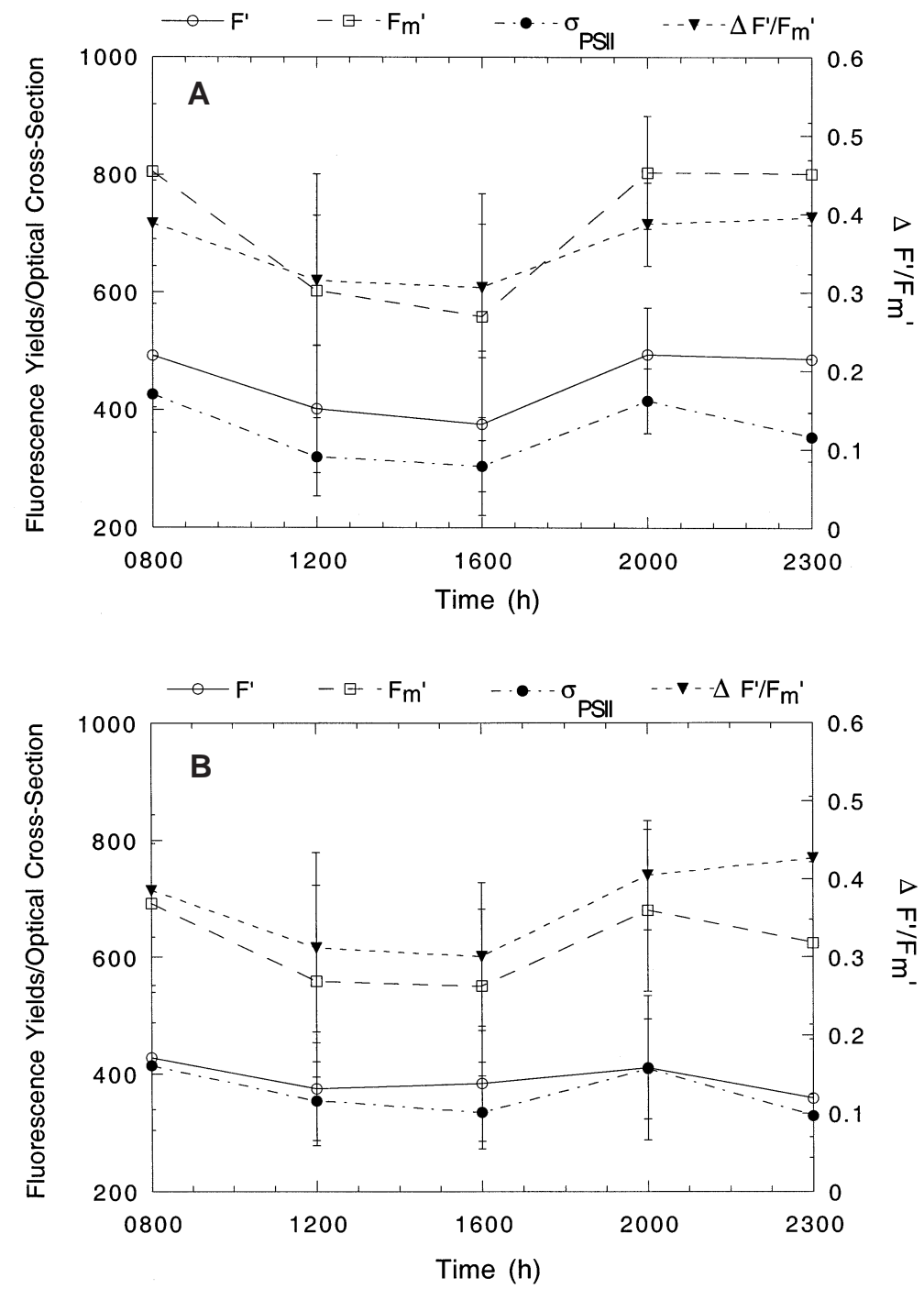

Fig. 2. Diel cycle of in situ steady-state (= light acclimatized) and dark acclimated chlorophyll fluorescence yields, including the quantum yield of chlorophyll fluorescence $\left(\Delta F^{\prime} / F_{\mathrm{m}}^{\prime}\right)$ in PSII, and the functional absorption cross-section $\left(\sigma_{\mathrm{PSII}}\right)$ for PSII. Mean $( \pm \mathrm{SD})$ of 6 samples. (A) Montastraea faveolata, (B) M. cavernosa. See Table 1 for abbreviation definitions

0.05). The functional absorption cross-section $\left(\sigma_{\mathrm{PSII}}\right)$ exhibited significant effects of time (ANOVA: $p=0.0001$ ), with early morning (08:00 h) and early evening (20:00 h) values significantly different from each other and all other measurements (SNK: $\mathrm{p}<0.05$ ).

Net photosynthesis and respiration, normalized to surface area, showed a similar pattern for both Montastraea faveolata and M. cavernosa (Fig. 3). A significant effect of time (ANOVA: $p=0.0001$ and $p=0.0001$ respectively) was observed, with rates of net photosynthesis always higher in $M$. faveolata and mid-day rates of photosynthesis significantly (SNK: p < 0.05) higher in both species than at any other time of measurement. Net photosynthesis normalized to chlorophyll a showed the exact same pattern (data not presented). For both species, rates of net photosynthesis were directly related to irradiance, while quantum yields of chlorophyll fluorescence taken on the same samples at the same time of day were inversely related to irradiance. As described for net photosynthesis, non-photochemical quenching ( $q N$, Fig. 3) of chlorophyll fluorescence from PSII exhibited a diel cycle and was significantly greater at mid-day for both $M$. faveolata (ANOVA: $\mathrm{p}=0.0001$, SNK: $\mathrm{p}<0.05$ ) and $M$. cavernosa (ANOVA: $p=0.018$, SNK: $\mathrm{p}<0.05)$. Additionally, in both species $q N$ was lowest at night (SNK: $p<0.05$ ), approaching zero.

In both 1998 and 1999 (Fig. 4A,B) the quantum yield of chlorophyll fluorescence $\left(\Delta F^{\prime} / F_{\mathrm{m}}{ }^{\prime}\right)$ in samples of Montastraea faveolata collected over the bathymetric range of 3 to $23 \mathrm{~m}$ (1998) or 3 to $30 \mathrm{~m}$ (1999) showed a significant effect of depth (ANOVA: $\mathrm{p}=$ 0.0001). In $1998 \Delta F^{\prime} / F_{\mathrm{m}}^{\prime}$ significantly increases with depth from 3 to $10 \mathrm{~m}$. In 1999 there is a very clear and significant increase in $\Delta F^{\prime} / F_{\mathrm{m}}^{\prime}$ with depth or as irradiance decreases over the entire depth range. Shallower depths $(3,10 \mathrm{~m})$ have significantly (SNK: $\mathrm{p}<0.05$ ) lower $\Delta F^{\prime} / F_{\mathrm{m}}^{\prime}$ than deeper depths (17, 23, $30 \mathrm{~m}$; Fig. 4B). Additionally, in $1999 \sigma_{\text {PSII }}$ showed a significant (ANOVA: $\mathrm{p}<0.05$ ) increase with depth, but the only significant multiple comparison was between shallow depths (Rainbow Garden) and all other depths (SNK: p < 0.05, Fig. 4C).

During May and June 1998 recording temperature thermistor instruments detected 2 warming events associated with the intrusion of Bahama Bank water onto the Exuma Island chain . The second event, which began on May 27, increased temperatures to over $32^{\circ} \mathrm{C}$ by June 4 at Rainbow Garden ( 3 to $4 \mathrm{~m}$ ) from temperatures that were less than $27^{\circ} \mathrm{C}$. At Rainbow Garden tagged colonies of Montastraea faveolata were measured during the intrusion of Bahama Bank water before and after visible signs of bleaching occurred. Measurements before bleaching occurred revealed 2 distinct populations of corals, which were designated as Healthy and Bleached retrospectively after actual bleaching began. Based on measurements of $\Delta F^{\prime} / F_{\mathrm{m}}{ }^{\prime}$, predictions were made as to which colonies would eventually bleach (Fig. 5, Student's $t$-test, $p=0.007$ ). After visible paling of colonies at this site began, the tagged corals were re-measured. $100 \%$ of the colonies with significantly lower $\Delta F^{\prime} / F_{\mathrm{m}}{ }^{\prime}$ values (Fig. 5) before 

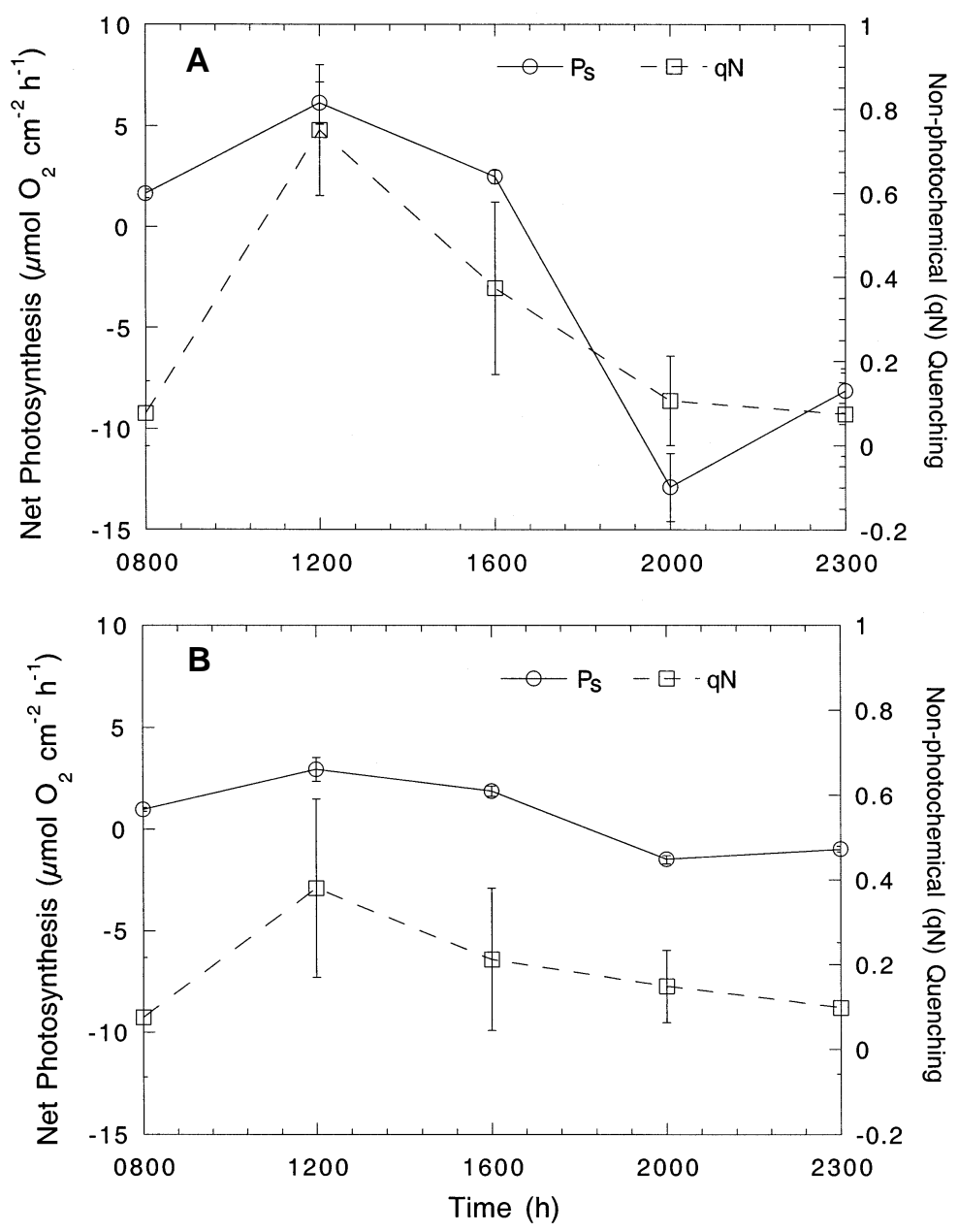

Fig. 3. Diel cycle of in situ measurements of net photosynthesis $\left(P_{\mathrm{s}}\right)$, and non-photochemical $(q N)$ quenching. Mean $( \pm \mathrm{SD})$ of 6 samples. (A) Montastraea faveolata, (B) M. cavernosa

visible signs of bleaching were evident bleached after an additional 3 to $4 \mathrm{~d}$ of exposure to elevated seawater temperatures; they continued to exhibit lower $\Delta F^{\prime} / F_{\mathrm{m}}{ }^{\prime}$ values (Fig. 5, Student's $t$-test, $\mathrm{p}=0.0009$ ). For both populations of corals, measurements of the functional absorption cross-section were not significantly different before (Student's $t$-test, $\mathrm{p}=0.81$ ) or after actual bleaching occurred (Student's $t$-test, $\mathrm{p}=0.23$ ).

\section{DISCUSSION}

An underwater fast repetition rate fluorometer (FRRF) (Gorbunov et al. 2000) has been used to characterize fluorescent and photosynthetic parameters on 2 dominant Caribbean reef-building corals. Ambient irradiance is an important factor that controls the fluorescence yields of these corals, as it does in other marine photoautotrophs (Falkowski \& Kolber 1995). As irradiance increases, $\Delta F^{\prime} / F_{\mathrm{m}}{ }^{\prime}$ decreases, as the excess energy from absorbed photons is dissipated as heat and fluorescence. Under nutrient-replete conditions, and independent of growth irradiance, the $F_{\mathrm{v}} / F_{\mathrm{m}}$ ratio averages 0.65 in a wide variety of phytoplankton species (Falkowski \& Kolber 1995), including zooxanthellae (Gorbunov et al. 2000). Measurements of zooxanthellae in hospite, however, have shown average $F_{\mathrm{v}} / F_{\mathrm{m}}$ values of about $0.39 \pm 0.07(\mathrm{~N}=350$, Gorbunov et al. 2000), well below the level characteristic for nutrient-replete microalgae. This lower efficiency of photochemical energy conversion of PSII in the zooxanthellae of corals is presumably due to the nitrogen limitation known to occur in these symbioses (Falkowski et al. 1993). It is also possible that upwelling or internal waves could episodically supply additional inorganic nitrogen, as has been reported for other reef systems (Leichter et al. 1996) and improve chlorophyll fluorescence yields. Nitrogen deficiency can result in a large proportion of inactive photosynthetic reaction centers (Kolber et al. 1988). The fraction of inactive reaction centers in zooxanthellae can be calculated as $1-\left(F_{\mathrm{v}} / F_{\mathrm{m}}\right) / 0.65$, where 0.65 is taken as the maximum potential quantum yield of chlorophyll fluorescence in PSII, $F_{\mathrm{v}} / F_{\mathrm{m}}$, for nutrient-replete cells (Falkowski $\&$ Kolber 1995). For example, in this study approximately $40 \%$ of reaction centers are inactive for Montastraea faveolata $\left(F_{\mathrm{v}} / F_{\mathrm{m}}=\right.$ 0.39 ) and $35 \%$ of reaction centers are inactive for $M$. cavernosa $\left(F_{\mathrm{v}} / F_{\mathrm{m}}=0.42\right)$.

For both species of coral, as ambient light intensity increased, both steady-state $\left(F^{\prime}\right)$ and maximum $\left(F_{\mathrm{m}}{ }^{\prime}\right)$ fluorescence yields decreased due to non-photochemical quenching $(q N)$ of chlorophyll fluorescence. The diel cycles observed in this study are similar to those previously reported for shallow corals (Brown et al. 1999, Hoegh-Guldberg \& Jones 1999, Ralph et al. 1999, Gorbunov et al. 2001). The magnitude, however, of the changes in fluorescence yields in this study were much smaller than observed for the shallow corals $(<5 \mathrm{~m})$ used in these other studies because of the lower irradiances at $17 \mathrm{~m}$ depth. This would suggest that corals at deeper depths are likely to have even smaller changes in fluorescent yields throughout the day. This would presumably lead to more efficient photochemical conversion of the available photons as the need to initiate protective mechanisms from over excitation of the photosynthetic apparatus is reduced, as suggested from the bathymetric data in this study (Fig. 4). Two 

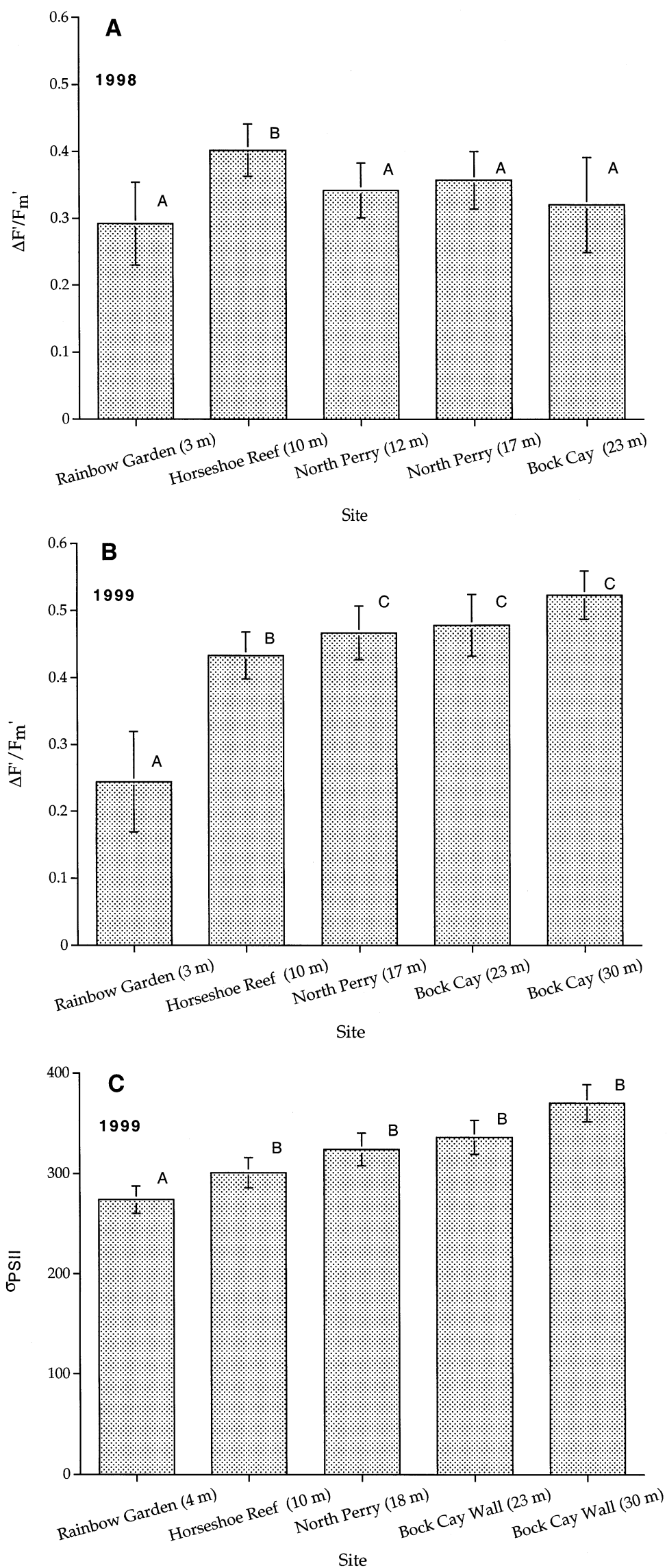

years of bathymetric data are presented in this study from the same time of year and place as well as under similar irradiances. The differences in the bathymetric patterns of $\Delta F^{\prime} / F_{\mathrm{m}}^{\prime}$ from 1998 to 1999 are not readily discernable but could be due to 2 reasons. First, the lower $\Delta F^{\prime} / F_{\mathrm{m}}{ }^{\prime}$ values in 1998 could have been a function of warmer water, since this data set was collected around the same time, but at least a week before, as the detection of warm Bahama Bank water on shallow reefs described above. Secondly, year-to-year variability in nutrient availability might also explain the differences. No data are available to support these hypotheses.

Several studies have shown reversible non-photochemical quenching in the zooxanthellae of corals that is correlated with either the xanthophyll cycle, the light-induced conversion of the carotenoid diadinoxanthin to diatoxanthin (Brown et al. 1999), or the photoinhibition of PSII (Brown et al. 1999, Hoegh-Guldberg \& Jones 1999, Ralph et al. 1999, Gorbunov et al. 2001). Mid-day reductions of chlorophyll fluorescence can be caused by the thermal dissipation of excess excitation energy either in the light-harvesting antennae or in the reaction centers of PSII (Vassiliev et al. 1994). As predicted by biophysical models, quenching within the reaction center is associated with a decrease in $\Delta F^{\prime} / F_{\mathrm{m}}$ ' without a change in $\sigma_{\text {PSII }}$, while quenching in the antennae bed leads to a decrease in $\sigma_{\text {PSII }}$ (Vassiliev et al. 1994). Antenna bed quenching should be correlated with the xanthophyll cycle (Demmig-Adams \& Adams 1996) and is a well-described photoprotective mechanism in higher plants and algae. Additionally, photoinhibitory damage to the reaction centers of PSII could also occur in the zooxanthellae of corals and would require de novo synthesis of the $Q_{\mathrm{b}}$-building protein D1, which results in a much slower recovery (Kyle et al. 1984). The patterns of change for fluorescent yields over a daily cycle from this study could be interpreted as being consistent with dynamic photoinhibition mediated by non-photochemical quenching in

Fig. 4. In situ measurements of $(\mathrm{A}, \mathrm{B})$ the quantum yield of chlorophyll fluorescence in PSII $\left(\Delta F^{\prime} / F_{\mathrm{m}}{ }^{\prime}\right)$ in 1998 (A) and 1999 (B) and (C) the functional absorption crosssection of PSII $\left(\sigma_{\mathrm{PSII}}\right)$ for the coral Montastraea faveolata over the bathymetric range of 3 to $23 \mathrm{~m}$ (1998) and 3 to $30 \mathrm{~m}$ (1999). All measurements were made between 09:00 and 10:00 h on sunny cloudless days. Mean $( \pm$ SD) of 10 samples. Depths with common superscripts were not significantly different from one another (SNK: $p>0.05$ ) 


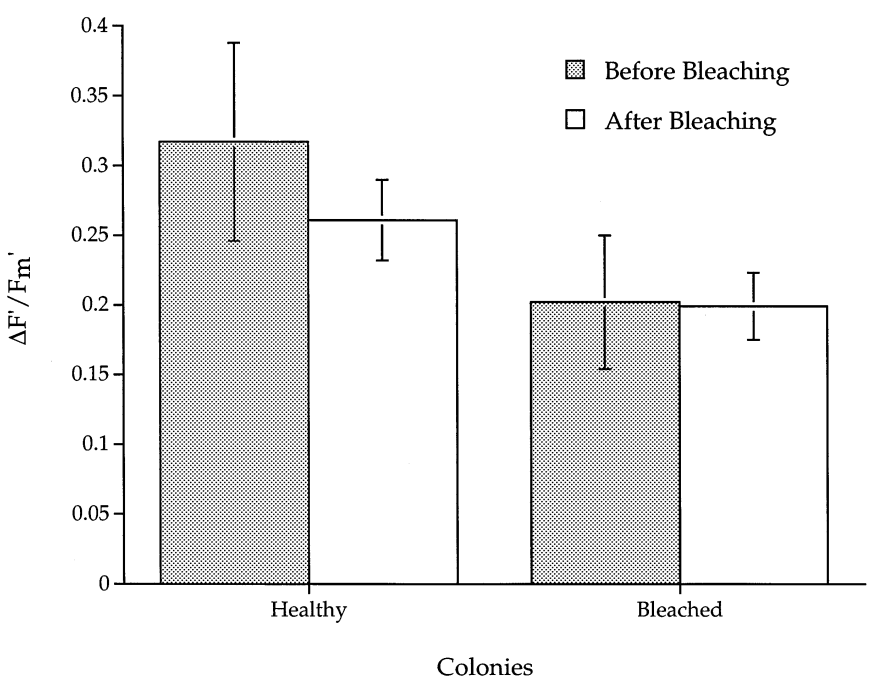

Fig. 5. In situ measurements of the quantum yield of chlorophyll fluorescence in PSII $\left(\Delta F^{\prime} / F_{\mathrm{m}}{ }^{\prime}\right)$ at steady-state in bleached (= Bleached) and non-bleached (= Healthy) colonies of the coral Montastraea faveolata from Rainbow Garden, Lee Stocking Island, before and after actual bleaching (colony paling visible). Mean $( \pm \mathrm{SD}), \mathrm{N}=7$ corals

both the reaction center and the antenna pigment bed. The mid-day decline in $\Delta F^{\prime} / F_{\mathrm{m}}^{\prime}$ is accompanied by a decrease in $F^{\prime}$, which has been interpreted as a regulatory down regulation of PSII fluorescence by nonphotochemical quenching (Krause \& Weis 1991); the simultaneous decrease in $\sigma_{\mathrm{PSII}}$ with decreasing $\Delta F^{\prime} / F_{\mathrm{m}}{ }^{\prime}$ is regulatory in nature as opposed to indicating damage to PSII (Falkowski \& Kolber 1995, Samson \& Bruce 1996, Gorbunov et al. 2001). This pattern of parallel changes in $\Delta F^{\prime} / F_{\mathrm{m}}{ }^{\prime}$ and $\sigma_{\mathrm{PSII}}$ is also observed in the bathymetric data. Dynamic photoinhibition at mid-day protects the reaction center, via thermal dissipation, from excess photon absorption, but photosynthetic electron transport is still saturated and results in high mid-day rates of net photosynthesis. Since it is believed that coral host and zooxanthellae respiration also increases proportionally with increasing light levels due to the availability of photosynthate, the pattern would be similar if gross photosynthesis could have been measured.

FRRFs can be used to take chlorophyll fluorescence yield measurements in situ and those measurements can then be used to make predictions about the photosynthetic competency of zooxanthellate corals under a variety of conditions. The ability to measure the in situ functional absorption cross-section along with other fluorescence parameters adds significantly to the biophysical and physiological interpretation of changes in fluorescence yields in corals and other photoautotrophs. In this study FFRFs were able to detect diel and bathymetric variability in $\Delta F^{\prime} / F_{\mathrm{m}}{ }^{\prime}$ that can be used to understand photoacclimatization processes nondestructively. Additionally, FRRFs moored on benthic platforms are capable of resolving the diel cycling of photosynthetic performance in corals for long deployments (e.g., weeks to months) with high temporal resolution on the order of minutes (Gorbunov et al. 2001). FRRFs also predicted which corals in a mixed field population were more susceptible to bleaching before any visible signs of bleaching were observed. Many of the non-bleached colonies (i.e., designated as Healthy) eventually showed signs of bleaching several days after the end of the study described above (R. Rowan pers. comm.). These corals, however, appear to have a higher rate of recovery compared to the more temperature-sensitive colonies, most of which were dead 1 yr later (M.P.L. unpubl.). These results point out an opportunity to actually predict the recovery potential of corals subjected to elevated seawater temperatures that resulted in bleaching. Since FRRFs can readily detect both intra-specific and intra-colony variability in the quantum yield of chlorophyll fluorescence, they should be a useful tool for non-destructive studies of photoacclimatization in corals under a variety of natural and experimental conditions.

Acknowledgements. This work was funded in part by a grant from the NOAA National Undersea Research Program through the Caribbean Marine Research Center at Lee Stocking Island, Bahamas. The views expressed herein are those of the authors and do not necessarily reflect the views of the NOAA or any of its sub agencies. Additional support was provided by the Office of Naval Research Environmental Optics Program under Grant No. 97PR00617-00 to M.P.L. We would like to thank the staff of Caribbean Marine Research Center at Lee Stocking Island for providing the field temperature data and excellent support during this work.

\section{LITERATURE CITED}

Asada K, Takahashi M (1987) Production and scavenging of active oxygen in photosynthesis. In: Kyle DJ et al. (eds) Photoinhibition. Elsevier, Amsterdam, p 228-287

Brown BE, Ambarsari I, Warner ME, Fitt WK, Dunne RP, Gibb SW, Cummings DG (1999) Diurnal changes in photochemical efficiency and xanthophyll concentrations in shallow water reef corals: evidence for photoinhibition and photoprotection. Coral Reefs 18:99-105

Butler WL (1972) On the primary nature of fluorescence yield changes associated with photosynthesis. Proc Natl Acad Sci USA 69:3420-3422

Demmig-Adams B, Adams WW III (1996) The role of xanthophyll cycle carotenoids in the protection of photosynthesis. Trends Plant Sci 1:21-26

Falkowski PG, Kolber Z (1995) Variations in chlorophyll fluorescence yields in phytoplankton in the world oceans. Aust J Plant Physiol 22:341-355

Falkowski PG, Dubinsky Z, Muscatine L, McCloskey L (1993) Population control in symbiotic corals. Bioscience 43: 606-611

Genty B, Briantais JM, Baker NR (1989) The relationship 
between the quantum yield of photosynthetic electron transport and quenching of chlorophyll fluorescence. Biochim Biophys Acta 990:87-92

Genty B, Harbinson J, Briantais JM, Baker NR (1990) The relationship between non-photochemical quenching of chlorophyll fluorescence and the rate of photosystem-2 photochemistry in leaves. Photosynth Res 25:249-257

Glynn PW (1993) Coral reef bleaching: ecological perspectives. Coral Reefs 12:1-17

Gorbunov M, Falkowski PG, Kolber Z (2000) Measurement of photosynthetic parameters in benthic organisms in situ using a SCUBA-based fast repetition rate fluorometer. Limnol Oceanogr 45:242-245

Gorbunov M, Kolber ZS, Lesser MP, Falkowski PG (2001) Photosynthesis and photoprotection in symbiotic corals. Limnol Oceanogr 46:75-85

Hoegh-Guldberg O, Jones RJ (1999) Photoinhibition and photoprotection in symbiotic dinoflagellates from reef-building corals. Mar Ecol Prog Ser 183:73-86

Iglesias-Prieto R, Matta JL, Robins WA, Trench RK (1992) Photosynthetic response to elevated temperature in the symbiotic dinoflagellate Symbiodinium microadriaticum in culture. Proc Natl Acad Sci USA 89:10302-10305

Jones RJ, Hoegh-Guldberg O, Larkum AWD, Schreiber U (1998) Temperature-induced bleaching of corals begins with impairment of the $\mathrm{CO}_{2}$ fixation mechanism in zooxanthellae. Plant Cell Environ 21:1219-1230

Kautsky H, Hirsh A (1931) Neue Versuche zur Kohlensauerassimilation. Naturwissenschaften 48:964

Kirk JTO (1994) Light and photosynthesis in aquatic ecosystems. Cambridge University Press, London

Kolber Z, Zehr J, Falkowski PG (1988) Effects of growth irradiance and nitrogen limitation on photosynthetic energy conversion in Photosystem II. Plant Physiol 88:72-79

Kolber Z, Prasil O, Falkowski PG (1998) Measurements of variable chlorophyll fluorescence using fast repetition rate techniques: defining methodology and experimental protocols. Biochem Biophys Acta 1367:88-106

Krause GH, Weis H (1991) Chlorophyll fluorescence: the basics. Annu Rev Plant Physiol Plant Mol Biol 42:313-349

Kyle DJ, Ohad I, Arntzen CJ (1984) Membrane protein damage and repair: selective loss of a quinone-protein function in chloroplast membranes. Proc Natl Acad Sci USA 81:4070-4074

Editorial responsibility: Otto Kinne (Editor),

Oldendorf/Luhe, Germany
Leichter JJ, Wing SR, Miller SL, Denny MW (1996) Pulsed delivery of subthermocline water to Conch Reef (Florida Keys) by internal tidal bores. Limnol Oceanogr 41: 1490-1501

Lesser MP (1996) Exposure of symbiotic dinoflagellates to elevated temperatures and ultraviolet radiation causes oxidative stress and inhibits photosynthesis. Limnol Oceanogr 41:271-283

Lesser MP, Stochaj WR, Tapley DW, Shick JM (1990) Bleaching in coral reef anthozoans: effects of irradiance, ultraviolet radiation and temperature, on the activities of protective enzymes against active oxygen. Coral Reefs 8: 225-232

Marsh JA (1970) Primary productivity of reef-building calcareous algae. Ecology 51:255-263

Ralph PJ, Gademann R, Larkum AWD, Schreiber U (1999) In situ underwater measurements of photosynthetic activity of coral zooxanthellae and other reef-dwelling dinoflagellate endosymbionts. Mar Ecol Prog Ser 180:139-147

Samson G, Bruce D (1996) Origins of the low yield of chlorophyll a fluorescence induced by single turnover flash in spinach thylakoids. Biochem Biophys Acta 1276:147-153

Schreiber U, Schliwa U, Bilger W (1986) Continuous recording of photochemical and non-photochemical chlorophyll fluorescence quenching with a new type of modulation fluorometer. Photosynth Res 10:51-62

van Kooten O, Snel JFH (1990) The use of chlorophyll fluorescence nomenclature in plant stress physiology. Photosynth Res 25:147-150

Vassiliev IR, Prasil O, Wyman KD, Kolber Z, Hanson AK, Prentice JE, Falkowski PG (1994) Inhibition of PSII photochemistry by PAR and UV radiation in natural phytoplankton communities. Photosynth Res 42:51-64

Vincent WF (1980) Mechanisms of rapid photosynthetic adaptation in natural phytoplankton communities. 2. Changes in photochemical capacity as measured by DCMUinduced chlorophyll fluorescence. J Phycol 20:201-211

Warner ME, Fitt WK, Schmidt GW (1996) The effect of elevated temperature on the photosynthetic efficiency of zooxanthellae in hospite from four different species of reef coral: a novel approach. Plant Cell Environ 19:291-299

Warner ME, Fitt WK, Schmidt GW (1999) Damage to photosystem II in symbiotic dinoflagellates: a determinant of coral bleaching. Proc Natl Acad Sci USA 96:8007-8012

Submitted: August 8, 2000; Accepted: November 23, 2000 Proofs received from author(s): February 23, 2001 